\section{Os ideólogos da brasilidade: as metamorfoses do mito nacional e a necessidade teórica e política de sua superação}

MACIEL, Fabrício. O Brasil-nação como ideologia. A construção retórica e sociopolítica da identidade nacional. Rio de Janeiro: Autografia, 2020.

Marcos Abraão Ribeiro (https://orcid.org/ 0000-0002-6185-2448)' Instituto Federal Fluminense, Rio de Janeiro, RJ, Brasil.

1 ma das questões centrais da intelectualidade bras ileira é desvendar a identidade nacional e as características que a conformam. A ênfase no nacional, inclusive, tem um caráter obsessivo na América Latina, o que explica a recorrência do tema da identidade (Ortiz, 2013: 609). "Diversos autores se debruçaram sobre a questão, como José Bonifácio, Tavares Bastos, Silvio Romero, Oliveira Vianna, Gilberto Freyre, Sérgio Buarque de Holanda, Roberto DaMatta, e, cada qual a seu modo, buscaram interpretar a singularidade brasileira" (Tavolaro, 2014).

Além dos autores que buscaram apresentar os elementos centrais da brasilidade, também houve importantes trabalhos que trouxeram como objetivo analisar essas interpretações, como os livros de Dante Moreira Leite (1976), Carlos Guilherme Mota (1978), Renato Ortiz (2008; 2013) e José Carlos Reis (2007). O livro resenhado, portanto, insere-se nessa importante tradição que analisa criticamente os trabalhos que procuram interpretar a identidade nacional.

A segunda edição de Brasil-nação como ideologia ${ }^{1}$ vem em um momento crucial, pois a eleição do primeiro presidente, reconhecidamente de extrema direita, o capitão reformado do Exército e ex-deputado federal, Jair Messias Bolsonaro (sem partido), fez com que símbolos da identidade brasileira voltassem à ordem do dia, como a negação do racismo e dos conflitos sociais, o discurso dos valores da família e da religião cristã e a crítica à "ideologia de gênero".

Para sustentar o caráter extremamente conservador da identidade nacional e defender a necessidade teórica e política de romper com o mito da brasilidade, Fabrício Maciel divide o livro, além da "Introdução", em cinco capítulos, conclusão e
Recebido: 30.07.20 Aprovado: 16.12 .20

\footnotetext{
I. Marcos Abraão Ribeiro é doutor em sociologia política pela Universidade Estadual do Norte Fluminense Darcy Ribeiro, Brasil (2015), professor e pesquisador do Instituto Federal Fluminense, campus Campos Centro, Rio de Janeiro, Brasil. <olamarcos@yahoo. com.br>
1. Para a segunda edição do livro, Fabrício Maciel realizou importantes modificações, o que ampliou o tamanho da obra e os argumentos presentes na primeira edição. Quando comparadas, pode-se citar a presença de um posfácio, que analisa as implicações do mito da brasilidade no Brasil governado por Jair Messias Bolsonaro.


posfácio, cujos elementos principais serão apresentados para, a seguir, fazer algumas observações sobre a obra resenhada.

$\mathrm{Na}$ "Introdução", Maciel apresenta a centralidade do tema da identidade nacional entre os brasileiros desde a independência, no século XIX, responsável por perpetuar a imagem de singularidade do Brasil. O autor expõe sua perspectiva teórico-metodológica que estrutura a abordagem, através do conceito de ideologia, do sociólogo húngaro Karl Mannheim, e sua concepção sobre a vinculação social das ideias. Dessa forma, seria possível analisar os ideólogos da brasilidade, cujas obras foram realizadas em momentos de crise na história do país. O autor apresenta os intérpretes que serão analisados nos cincos capítulos que compõem o livro - José Bonifácio, Gilberto Freyre, Roberto DaMatta e Marilena Chauí, e também a interpretação de Joaquim Nabuco sobre a contradição entre a nação ideal de Bonifácio e a nação real existente na sociedade escravista, que ele utilizará como fio condutor para a crítica ao caráter ideológico e conservador do mito da brasilidade.

No primeiro capítulo, Maciel expõe o pensamento de José Bonifácio, o iniciador dos elogiadores ufanistas do Brasil. Aplica a metodologia apresentada na "Introdução" e analisa o pensamento de Bonifácio contextualizando-o em relação às grandes questões de sua época, que eram liberalismo e monarquia. Maciel aponta que o pensamento liberal de Bonifácio tinha como objetivo transformar a sociedade patriarcal em sociedade impessoal, moderna e livre, fazendo com que os escravos fossem transformados em consumidores e os índios em indivíduos civilizados. Maciel defende que o patriarca da independência formulou uma imagem idealizada do Brasil, a partir da exaltação do território e da bondade do que, em uma realidade marcada pela escravidão, representava uma presença ideológica da nação, compreendida como comunidade abstrata. O povo seria marcado pela ingenuidade e fraqueza que, por sua vez, demonstraria a necessidade de as elites econômicas brasileiras comandarem o povo através de um Estado forte, pois a responsabilidade recairia sobre as Cortes de Lisboa. Além de idealizar a nação, Bonifácio construiu uma interpretação que inferioriza índios e negros, quando comparados aos brancos, pois não seriam brasileiros. Maciel demonstra, de forma acurada, como a presença de princípios antitéticos foi fundamental para a formulação do mito nacional baseado em sentimentos mágicos, pois Bonifácio inaugura o imaginário nacional mágico, cuja crença é a de que os dilemas seriam resolvidos pela vontade de Deus. Através de Bonifácio, constitui-se um cosmos composto pela junção das esferas da natureza, da religião e da política. O patriarca da independência funda, portanto, o mito Brasil, que seria o melhor lugar natural para se viver no mundo. Ao mesmo tempo, Maciel observa que, para Bonifácio, era necessário convencer a todos de que a classe dominante teria as condições para conduzir a nação no processo de 
modernização. Como será visto no capítulo seguinte, esse argumento também está presente em Gilberto Freyre. O primeiro capítulo tem uma importância central para o livro resenhado. Nele o autor apresenta a gênese do mito da brasilidade, seus componentes centrais e suas consequências, teóricas e políticas, pois será o principal entrave para o entendimento dos reais problemas existentes no Brasil.

No segundo capítulo, Maciel apresenta a interpretação crítica de Joaquim Nabuco sobre a escravidão, formulada no final do Império, com o objetivo de utilizá-la como base para contrapor ao mito da brasilidade. Através da obra de Nabuco, Maciel procura sustentar a dualidade nação ideal- nação real, o caráter ideológico contido na leitura de Bonifácio, a força social das ideias e o papel da escravidão como principal chaga nacional. A escravidão seria a grande instituição brasileira desde o Brasil colônia, ou seja, a instituição estruturante e classificadora da vida nacional.

No terceiro capítulo, Maciel analisa a obra de Gilberto Freyre produzida durante a "Era Vargas", com o objetivo de demonstrar os principais argumentos utilizados pelo sociólogo pernambucano para a formulação da singular identidade brasileira. O autor procura demonstrar como Freyre, mesmo estando em um contexto diferente daquele vivido por José Bonifácio, atualiza a interpretação culturalista e essencialista sobre o Brasil. Precisamente, Maciel procura apresentar como Freyre constrói a ideologia da identidade nacional e, o mais importante, como ela se reflete no imaginário popular e na ação política concreta (p. 84). Maciel sinaliza, com cuidado analítico, como Freyre admite a existência de um sincretismo cultural singular entre os brasileiros pois a cultura de brancos, indígenas e negros teria tido uma importância específica que resultou na presença em lugares naturalmente diferenciados e coligados pela família patriarcal e a religião, as duas instituições brasileiras fundamentais (p. 85). A partir das duas instituições supracitadas, Freyre apresenta a vida cotidiana como o elemento decisivo para a expressão do caráter brasileiro e de sua reprodução social.

De acordo com Freyre, a composição família-religião possui o papel central para justificar a ausência de preconceito étnico na cultura brasileira (p. 87). O elemento religioso tem uma função decisiva como meio de unificação política e econômica da nação, como já aparecera no argumento de José Bonifácio. No caso específico de Freyre, o catolicismo funcionou como o cimento simbólico da nacionalidade. E esta suposta singularidade é observada por Freyre como elemento positivo, o que gerou a legitimação da saída autoritária liderada por Getúlio Vargas (p. 88). No argumento de Freyre, portanto, estão amalgamados os extremos opostos liberdade e autoridade, na medida em que apenas um governo forte poderia evitar a fragmentação e a anarquia social. Como consequência, a democracia seria representada pela cultura luso-brasileira, fazendo com que a preservação da nação fosse o elemento decisivo, 
mesmo se em detrimento da democracia política. Seguindo Bonifácio, a interpretação freyriana repete uma perspectiva que naturaliza a realidade e apaga as importantes contradições sociais que marcam nosso país. Assim, o autoritarismo político possui elementos para não ser questionado, pois os regimes autoritários seriam os mais adequados ao caso brasileiro (p. 93). Ter-se-ia uma singularidade como miscigenação em todos os aspectos. Maciel advoga que Freyre é o grande ideólogo da unidade nacional, ou seja, o inventor da tradição luso-brasileira que, por sua vez, mais omite que explica o Brasil.

A questão da natureza é outro elemento central para transformar fenômenos sociais em ações espontâneas, o que também funciona como justificativa para as saídas autoritárias na vida política: "Isso sugere uma combinação mágica, como uma espécie de relação dialética sem conflito, onde cada qual contribui com uma especificidade natural sem se prejudicar por isso" (p. 99). Segundo Maciel, Freyre constrói a totalidade nacional através de uma perspectiva holista e harmonizadora, continuando e aperfeiçoando o mito nacional construído por José Bonifácio.

No quarto capítulo, Maciel expõe a interpretação de Roberto DaMatta sobre a brasilidade, formulada durante a ditadura civil-militar, em 1978, e a crítica realizada por Jessé Souza, para sustentar que DaMatta tem uma perspectiva interpretativa que aparenta romper com o mito nacional, mas que termina atualizando-o. Para tanto, Maciel aponta as similitudes entre DaMatta e Freyre, que teria sido o grande influenciador do antropólogo no estilo e nas interpretações.

DaMatta sustenta que teria exposto a gramática profunda dos conflitos sociais brasileiros através da dualidade indivíduo-pessoa, que dividiria o país em oficial e cotidiano. Seríamos marcados pelo jeitinho brasileiro, maneira original e nacional de viver, e por uma tradição católica, representativa de nosso atraso (p. 117). Seguindo Bonifácio e Freyre, DaMatta defende, portanto, que o Brasil possui uma irredutível singularidade.

Apoiando-se em Jessé Souza, Maciel argumenta que o antropólogo Roberto DaMatta não explica como o dualismo se articula e se institucionaliza, além de apontar como a permanência do personalismo tradicionalista atua como impedimento para a tematização de valores e classes sociais. O dualismo damattiano, portanto, seria insustentável, pois apenas sistematiza o senso comum (p. 126). A inserção de DaMatta é central ao trabalho de Maciel, porque o antropólogo defende teses tradicionalistas no Brasil moderno, como o hibridismo e o personalismo que atualizaram o mito da brasilidade (p. 130). 
No quinto capítulo, Maciel apresenta o trabalho da filósofa Marilena Chauí sobre o autoritarismo brasileiro, publicado em 2000, ano em que o Brasil completava 500 anos de história. O autor expõe os pontos positivos do livro da filósofa uspiana, como a distinção entre formação e fundação, que Maciel utiliza para reforçar sua crítica aos ideólogos da brasilidade. O autor também mostra, de maneira bastante convincente, a contradição interna presente na interpretação de Chauí, que, apesar de propor uma interpretação crítica, acaba reproduzindo uma visão filosófica e religiosa do culturalismo atávico presente nos ideólogos da brasilidade.

Maciel conclui o seu trabalho argumentando sobre o conteúdo da ideologia da brasilidade, consolidado pelo composto mágico deus - política - homem - natureza ( $p$. 149), que foi responsável por reproduzir uma ideologia que oculta as contradições sociais. A necessidade de responder ao que somos transformou os autores, que buscaram a nossa singularidade, nos maiores representantes da ideologia da brasilidade. Assim, o autor demonstra a necessidade de fazer com que o Brasil real possa interpelar o Brasil ideal de modo que possa abandonar o mito nacional para ter condições de enfrentar os reais problemas.

No "Posfácio", Maciel aborda a metamorfose do mito nacional no governo Jair Bolsonaro. O slogan Deus acima de todos, por exemplo, representa a atualização do composto mágico da brasilidade (p. 163). A partir da crítica de Nabuco, Maciel afirma que não existe progresso a partir do rebaixamento da dignidade popular, como ocorreu, por exemplo, com a reforma trabalhista realizada pelo governo Michel Temer (MDB). Conjuntamente, o autor reafirma o papel do mito como legitimador das ações do Estado, bem como critica a novelização da política realizada pela grande mídia, através da narrativa da corrupção. Maciel apresenta o caso da barragem da Vale do Rio Doce em Brumadinho-MG para sustentar que a desigualdade derivada do capitalismo global, que generaliza a indignidade, é a grande responsável por explicar os dilemas do Brasil real encobertos pelo mito da brasilidade. Ao sustentar que a desigualdade é o grande problema, Maciel reafirma a necessidade de se romper teórica e politicamente com a identidade nacional construída pelos ideólogos do mito da brasilidade.

O livro de Fabrício Maciel possui méritos em termos intelectuais e políticos, pois discutir, de maneira crítica o mito nacional neste momento difícil da história brasileira, é uma atitude fundamental. O livro demarca a necessidade de romper com as tradicionais imagens do Brasil, de viés culturalista, para que o país possa ser interpretado como integrante da modernidade global (Domingues, 2013). A ruptura com o mito da brasilidade, portanto, é um caminho crucial para deixar de lado o complexo de inferioridade que nos impede de produzir teoria de alcance global (Lynch, 2013). Do ponto de vista político, a crítica ao mito nacional mostra como ele exerce o papel de 
entrave cognitivo para que se possa criar alternativas políticas que tenham condições de enfrentar os graves problemas do Brasil real e formular alternativas progressistas.

Em um cenário de crise, o papel do intelectual se torna decisivo, como sugere o livro resenhado. Assim, seria muito importante aos estudiosos do Brasil apresentarem o lugar da identidade nacional em um mundo globalizado, como alternativa interpretativa concreta para se analisar a identidade nacional, que, por sua vez, coloca como desafio produzir uma história global com maior equilíbrio (Ortiz, 2013: 624). O livro de Fabrício Maciel representa uma grande contribuição para romper com uma narrativa eurocêntrica e idealizada do Ocidente, que é decisiva em nossa identidade nacional, e nos repensarmos teórica e politicamente.

\section{Referências}

DOMINGUES, José Maurício. Modernidade global e civilização contemporânea: para uma renovação da teoria crítica. Belo Horizonte: Editora UFMG, 2013.

LEITE, Dante Moreira. O caráter nacional brasileiro. 3 ed. São Paulo: Pioneira, 1976. LYNCH, Christian. Por que pensamento e não teoria? A imaginação político-social brasileira e o fantasma da condição periférica (1880-1970). Dados - Revista de Ciências Sociais, v. 56, n. 4, p. 727-767, 2013.

MACIEL, Fabrício. O Brasil-nação como ideologia. A construção retórica e sociopolítica da identidade nacional. São Paulo: Annablume, 2007.

O Brasil-nação como ideologia. A construção retórica e sociopolítica da identidade nacional. Rio de Janeiro: Autografia, 2020.

MOTA, Carlos Guilherme. Ideologia da cultura brasileira (1933-1974). 4 ed. São Paulo: Ática, 1978.

ORTIZ, Renato. Imagens do Brasil. Revista Sociedade e Estado, v. 28, n. 3, p.609-633, Set./Dez. 2013.

Cultura brasileira e identidade nacional. 5. ed. São Paulo: Brasiliense, 2008.

REIS, José Carlos. As identidades do Brasil: De Varnhagen a FHC. Rio de Janeiro: Editora FGV, 2007.

TAVOLARO, Sérgio. A tese da singularidade brasileira revisitada: desafios teóricos contemporâneos. Dados - Revista de Ciências Sociais, v. 57, n.3, p. 633-673, 2014. 